\title{
Raised plasma arginine vasopressin concentrations during cluster headache attacks
}

\author{
R Franceschini, M Leandri, A Cataldi, E Bruno, G Corsini, E Rolandi, T Barreca
}

\begin{abstract}
To obtain data about peripheral concentrations of arginine vasopressin in head pain syndromes, the plasma arginine vasopressin secretory pattern in 12 adult male patients with cluster headache was evaluated. Blood samples for plasma arginine vasopressin and osmolality determinations were collected before, and at $15,30,45,60,90$, and 120 minutes during a cluster attack. Blood pressure was also monitored. The same sampling was repeated during an asymptomatic period. During cluster attacks, the mean values of plasma arginine vasopressin before an attack $(2 \cdot 3(0 \cdot 1) \mathrm{ng} / \mathrm{l})$ significantly increased, reaching their peak at 45 minutes (4.8 (0.5) ng/l; $P<0.01$ v baseline). No significant variations were found in mean arterial pressure and plasma osmolality. These data suggested involvement of neurotransmitter mechanisms regulating arginine vasopressin secretion and a possible role of arginine vasopressin in vasomotor phenomena accompanying cluster attacks.
\end{abstract}

(F Neurol Neurosurg Psychiatry 1995;59:381-383)

Keywords: cluster headache; arginine vasopressin; secretory profile

Some of the current views on the pathogenesis of cluster headache suggest a primary CNS dysfunction, in particular in the hypothalamus. ${ }^{1}$ At present, data on the pattern of plasma vasopressin in this kind of cephalalgia are not available. Increased plasma arginine vasopressin concentrations have been reported both in spontaneous ${ }^{2}$ and induced migraine attacks. ${ }^{3}$ Conversely, inhibition of arginine vasopressin secretion during migraine has also been found. ${ }^{4}$ To evaluate the arginine vasopressin secretory pattern in cluster headache, a syndrome that shares some pathophysiological mechanisms with migraine, we measured arginine vasopressin plasma concentrations in a group of patients with cluster headache, both during the cluster attack and in the asymptomatic period.

\section{Materials and methods}

Twelve adult men (age 23-63 years) who were attending the headache centre of the Department of Neurology at the University of Genoa for the first time, were admitted to hospital for the study. All patients had had episodic cluster headache, diagnosed according to the International Headache Society criteria. ${ }^{5}$ They were in the second to the fourth cluster period in their lifetime. None of the subjects were obese, alcoholic, or drug misusers. Ten subjects were smokers; these were asked to stop smoking three days before admission to hospital. Diabetes, atherosclerosis, and endocrine, kidney, and liver diseases were excluded by clinical and laboratory examination. None of the patients had ever been on prophylactic medication, nor was taking any medication known to interfere with the hypothalamopituitary axis. During the study day in the cluster period, only $\mathrm{O}_{2}$ inhalation for symptoms was permitted. Seven age and sex matched healthy subjects constituted the control group. All patients gave their informed consent.

\section{STUDY PROTOCOL}

The patients were studied on two occasions: during the first two weeks of a cluster period and during a symptom free period, at least two to three weeks after the complete remission of symptoms.

During the symptomatic period, blood samples were collected every two hours, starting at $800 \mathrm{am}$. Patients were asked to call medical personnel as soon as they became aware of the onset of the headache attack. Blood samples were then collected at 0,15 , $30,45,60,90$, and 120 minutes. The blood sample collected before the start of the attack was considered as baseline. In each patient, blood pressure was recorded at the time each sample was taken and the mean arterial pressure (diastolic pressure $+1 / 3$ pulse pressure) was determined. The duration and severity of pain were also assessed and reported verbally by the patients. The patients rated the severity of their headaches on a five point scale: 0 for no pain, 1 for mild pain, 2 for moderate pain, 3 for severe pain, and 4 for very severe pain.

In each patient, the study was repeated at the same times of day, during a symptom free period.

All blood samples were immediately transferred to chilled, siliconised, disposable glass tubes containing aprotinin (250 kIU) and EDTA $(7 \mathrm{mg})$. Blood was centrifuged at $4^{\circ} \mathrm{C}$, and the plasma obtained was frozen and stored at $-40^{\circ} \mathrm{C}$ until assayed.

\section{ASSAYS}

Plasma arginine vasopressin $(2 \mathrm{ml})$ was extracted and concentrated with small car- 
tridges packed with octadecasilyl silica (SEP-PAK cartridge): the arginine vasopressin standard was calibrated against the WHO 77/501 standard. The mean recovery of standard quantities added to plasma was $91 \%$. The antiserum was highly specific, and had less than $0.01 \%$ and $0.014 \%$ cross reactivity with oxytocin and vasotocin, respectively. The sensitivity of the assay was $1.2 \mathrm{ng} / \mathrm{l}$. The coefficients of variation within and between assays were $6 \cdot 1$ and $4.4 \%$, respectively. The normal range of our laboratory is $1 \cdot 2-5 \mathrm{ng} / \mathrm{l}$. In all plasma samples, osmolality was also measured with the freezing point depression method (Fiske osmometer model 330 D; Fiske, Uxbridge, MA, USA).

\section{STATISTICAL ANALYSIS}

Statistical evaluation of the results was carried out by means of a two tailed Student's $t$ test and analysis of variance (ANOVA), followed by the Tukey-Kramer multiple comparison test. The arginine vasopressin secretory area was calculated with the trapezoidal rule, after subtracting basal values, and correlation with the severity and duration of pain assessed by the linear regression method.

\section{Results}

The table and figure show the mean (SEM) data. The mean plasma arginine vasopressin values recorded before the onset of the attacks $(2 \cdot 3 \quad(0 \cdot 1) \mathrm{ng} / \mathrm{l})$ significantly $(F=4 \cdot 834$; $\mathrm{P}<0.01)$ increased, reaching the highest concentrations at 45 minutes $(4.8(0.5) \mathrm{ng} / \mathrm{l}$; $\mathrm{P}<0.01 v$ baseline, figure). The mean arginine vasopressin secretory areas recorded during cluster attacks $(221.8(35.6) \mathrm{ng} / 1 / \mathrm{min})$ were significantly $(P<0.01)$ higher than those recorded during the pain free period $(49.9(8.0) \mathrm{ng} / \mathrm{l} / \mathrm{min}$, table).

The arginine vasopressin increase occurred in the absence of contemporaneous variations in either plasma osmolality or mean arterial pressure values $(F=0.067$ and $F=0.461$ respectively; $P>0.05$, figure). There was no significant correlation between arginine vasopressin secretory areas and duration $(r=0.159 ; \mathrm{P}>0.05)$ or severity $(r=0.113$; $\mathrm{P}>0.05)$ of pain.

Clinical and hormonal data of the patients studied

\begin{tabular}{|c|c|c|c|c|c|c|c|c|c|}
\hline \multirow[b]{3}{*}{ Patient } & \multirow[b]{3}{*}{ Age (y) } & & & \multicolumn{6}{|c|}{ Arginine vasopressin } \\
\hline & & \multicolumn{2}{|c|}{ Cluster attacks } & \multicolumn{3}{|c|}{ Cluster attacks } & \multicolumn{3}{|c|}{ Pain free period } \\
\hline & & $\begin{array}{l}\text { Severity } \\
\text { Score }\end{array}$ & $\begin{array}{l}\text { Duration } \\
\text { (min) }\end{array}$ & $\begin{array}{l}\text { Base } \\
(n g / l)\end{array}$ & $\begin{array}{l}\text { Peak } \\
\text { (ng/l) }\end{array}$ & $\begin{array}{l}\text { Area } \\
\text { (ng/l/min) }\end{array}$ & $\begin{array}{l}\text { Base } \\
(n g / l)\end{array}$ & $\begin{array}{l}\text { Peak } \\
(n g / l)\end{array}$ & $\begin{array}{l}\text { Area } \\
\text { (ng/l/min) }\end{array}$ \\
\hline $\begin{array}{r}1 \\
2 \\
3 \\
4 \\
5 \\
6 \\
7 \\
8 \\
9 \\
10 \\
11 \\
12\end{array}$ & $\begin{array}{l}25 \\
34 \\
31 \\
23 \\
56 \\
41 \\
45 \\
28 \\
37 \\
63 \\
46 \\
51\end{array}$ & $\begin{array}{l}4 \\
3 \\
4 \\
3 \\
3 \\
2 \\
3 \\
4 \\
3 \\
3 \\
2 \\
4\end{array}$ & $\begin{array}{r}45 \\
75 \\
90 \\
90 \\
30 \\
75 \\
45 \\
75 \\
45 \\
75 \\
120 \\
105\end{array}$ & $\begin{array}{l}1.7 \\
2.5 \\
2 \cdot 8 \\
1.7 \\
2.5 \\
3 \cdot 2 \\
2.9 \\
1.7 \\
1.9 \\
2 \cdot 3 \\
2.2 \\
2.0\end{array}$ & $\begin{array}{l}3 \cdot 3 \\
6 \cdot 3 \\
6 \cdot 2 \\
5 \cdot 0 \\
6 \cdot 0 \\
6 \cdot 5 \\
9 \cdot 0 \\
6 \cdot 3 \\
4 \cdot 9 \\
5 \cdot 3 \\
2 \cdot 9 \\
2 \cdot 8\end{array}$ & $\begin{array}{r}138 \cdot 7 \\
299 \cdot 0 \\
261 \cdot 2 \\
344 \cdot 5 \\
282 \cdot 0 \\
78 \cdot 6 \\
243 \cdot 7 \\
212 \cdot 5 \\
304 \cdot 3 \\
420 \cdot 0 \\
44 \cdot 0 \\
33 \cdot 7\end{array}$ & $\begin{array}{l}2 \cdot 3 \\
2 \cdot 6 \\
2 \cdot 2 \\
2 \cdot 2 \\
2 \cdot 7 \\
3 \cdot 0 \\
2 \cdot 5 \\
2 \cdot 3 \\
2 \cdot 5 \\
2 \cdot 4 \\
2 \cdot 5 \\
2 \cdot 3\end{array}$ & $\begin{array}{l}2.5 \\
3.4 \\
3 \cdot 1 \\
3.3 \\
3.5 \\
3 \cdot 3 \\
3.0 \\
3 \cdot 1 \\
2.9 \\
3.8 \\
3.3 \\
3.3\end{array}$ & $\begin{array}{r}13 \cdot 7 \\
42.9 \\
74.2 \\
25 \cdot 7 \\
103 \cdot 2 \\
70 \cdot 7 \\
22 \cdot 7 \\
62 \cdot 0 \\
18 \cdot 0 \\
38 \cdot 3 \\
51 \cdot 2 \\
76.0\end{array}$ \\
\hline $\begin{array}{l}\text { mean } \\
\text { SEM }\end{array}$ & $\begin{array}{r}40 \cdot 1 \\
3 \cdot 7\end{array}$ & $\begin{array}{l}2.41 \\
0.23\end{array}$ & $\begin{array}{r}72 \cdot 5 \\
7.8\end{array}$ & $\begin{array}{l}2 \cdot 28 \\
0 \cdot 15\end{array}$ & $\begin{array}{l}5 \cdot 37^{\star} \\
0.51\end{array}$ & $\begin{array}{c}221 \cdot 8^{\star} \\
35 \cdot 6\end{array}$ & $\begin{array}{l}2.45 \\
0.07\end{array}$ & $\begin{array}{l}3.20 \\
0.09\end{array}$ & $\begin{array}{r}49 \cdot 9 \\
8.0\end{array}$ \\
\hline
\end{tabular}

$\star \mathrm{P}<0.01 v$ pain free period.
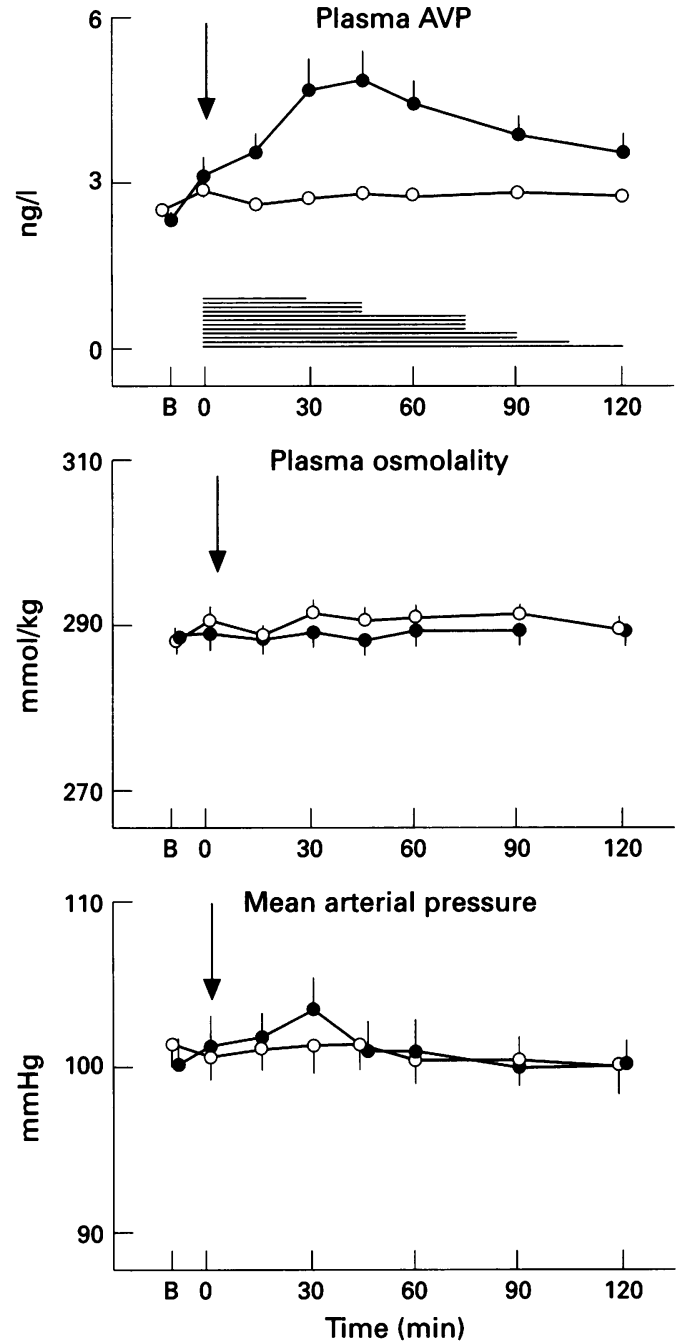

Combined data (mean(SEM)) from 12 patients with cluster headache showing the variations in plasma arginine vasopressin $(A V P)$, plasma osmolality, and mean arterial vasopressin $(A V P)$, plasma osmolality, and mean arterial period (O). The arrow indicates the start of the cluster attack. The horizontal lines indicate the duration of single attacks.

\section{Discussion}

Our data show that during cluster attacks plasma arginine vasopressin concentrations increase in the absence of nausea and variations in plasma osmolality or mean arterial pressure values, which are known to be potent stimuli of arginine vasopressin secretion. ${ }^{6}{ }^{7}$ This indicates that in cluster headache stimuli other than osmotic and baroreceptive are responsible for the increase in arginine vasopressin.

Stress has been cited as a possible cause of some hypothalamopituitary dysfunctions. In early studies ${ }^{8}$ in particular, increased arginine vasopressin secretion was reported in stressed animals. At present, however, there is no convincing evidence based on further in vivo studies that arginine vasopressin is released in response to stress. ${ }^{9}$ It is known that non-osmotic control of arginine vasopressin release undergoes neurotransmitter regulation. Experimental data indicate that serotonin plays a stimulatory part, ${ }^{10}$ whereas dopamine is mainly inhibitory. ${ }^{11}$ Experimental studies suggest that noradrenaline plays a 
modulatory part in arginine vasopressin secretion - that is, high hypothalamic noradrenergic concentrations stimulate, whereas low concentrations tonically inhibit arginine vasopressin release. ${ }^{12}$ Nociceptive inputs, particularly pain, stimulate arginine vasopressin secretion in humans. ${ }^{13}{ }^{14}$ It has been reported that the mechanisms by which noxious stimuli induce arginine vasopressin release from the neurohypophysis involve the A1 noradrenaline cell system, located in the caudal ventrolateral medulla. ${ }^{15}$ This cell system conveys afferent information from periphery to hypothalamic neurosecretory cells that secrete arginine vasopressin, through catecholaminergic pathways. ${ }^{16}$ This suggests that activation of a noradrenergic pathway is responsible for arginine vasopressin release during cluster attacks. This hypothesis seems to fit with other indications of a noradrenergic involvement in some hypothalamic endocrine dysfunctions recorded in patients with cluster headache. ${ }^{17}$ Alternatively, it is possible that the arginine vasopressin increase recorded in our patients may be related to activation of the serotoninergic pathway. It has been hypothesised that in vasomotor headaches the activation of cortical and limbic neuronal pathways leads to the release of seratonin by neurons of the brainstem. ${ }^{18}$ Thus seratonin may be the triggering factor both of the cascade of the vascular events that characterise vasomotor headaches, and of the arginine vasopressin release.

The pathophysiological importance of the increased concentrations of circulating arginine vasopressin during cluster attacks is at present unclear. Arginine vasopressin is known to be a potent vasoconstrictor. ${ }^{19}$ It has been postulated that constriction of both arterial and venous tributary vessels reduces the load on the cavernous sinus to such an extent that pain disappears. ${ }^{20}$ For this reason, arginine vasopressin might influence the duration and the severity of cluster attacks by exerting its vascular biological effects. In our patients a poor correlation between arginine vasopressin increase and duration or severity of pain was found. This may be due to individual differences in sensitivity threshold to pain and in the severity of the pain. Furthermore, it must be considered that, besides arginine vasopressin, several factors-for example, the integrity of some perivascular sympathetic fibres, circulating catecholamines, and other vasoactive mediators ${ }^{21}{ }^{22}$ - may condition the vasoconstriction that determines the end of pain.

1 Leone $M$, Bussone $G$. A review of hormonal findings in cluster headache. Evidence for hypothalamic involvecluster headache. Evidence for hypc

2 Hampton KK, Esack A, Peatfield RC, Grant PJ. Elevation of plasma vasopressin in spontaneous migraine. Cephalalgia 1991;11:249-50.

3 Peatfield RC, Hampton KK, Grant PJ. Plasma vasopressin levels in induced migraine attacks. Cephalalgia 1988;8: 55-7.

4 Poole CJM, Lightman SL. Inhibition of vasopressin secretion during migraine. I Neurol Neurosurg Psychiatry 1988;51:1441-4.

5 Headache Classification Committee of the International Headache Society. Classification and diagnostic criteria for headache disorders, cranial neuralgias and facial pain. Cephalalgia 1988;8:35-8.

6 Robertson GL. The regulation of vasopressin function in health and disease. Recent Prog Horm Res 1977;33: health and

7 Nussey SS, Hawthorn J, Page SR, Ang VTY, Jenkins JS Responses of plasma oxytocin and arginine vasopressin to nausea induced by apomorphine and ipecacuanha. Clin Endocrinol 1988;28:297.

8 Husain MK, Manger WM, Rock TW, Weiss RJ, Frantz AG. Vasopressin release due to manual restraint in the rat: role on body compression and comparison with other stressful stimuli. Endocrinology 1979;104:641-4.

9 Baylis PH. Regulation of vasopressin secretion. In: Water and salt homeostasis in health and disease. Bailliere's clinical endocrinology and metabolism 1989;3:313-30.

10 Iovino $M$, Steardo $L$. Effects of substances influencing brain serotoninergic transmission on plasma vasopressin brain serotoninergic transmission on plasma vasopre

11 Lightman SL, Forsling M. Evidence for dopamine as an inhibitor of vasopressin release in man. Clin Endocrinol 1980;12:39-46.

12 Veltmar A, Curman J, Qadri F, Rascher W, Unger T. Involvement of adrenergic and angiotensinergic receptors in the paraventricular nucleus in the angiotensin II-induced vasopressin release. $f$ Pharmacol Exp Ther 1992;263:1253-60.

13 Kendler KS, Weitzman EA, Fisher DA. The effect of pain on plasma arginine-vasopressin concentrations in man. Clin Endocrinol 1978;8:89-94.

14 Anderson ID, Forsling ML, Little RA, Payman JA. Acute injury is a potent stimulus for vasopressin release in man. injury is a potent stimulus for
$\mathcal{H}$ Physiol Lond $1989 ; 416: 28 \mathrm{P}$.

15 Day TA, Sbbald JR. Noxious somatic stimuli excite neurosecretory vasopressin cells via $\mathrm{Al}$ cell group. $\mathrm{Am}$ rosecretory vasopressin cells

16 Cunnigham ET, Sauchenko PE. Anatomical specificity of noradrenergic inputs to the paraventricular and supraoptic nuclei of the rat hypothalamus. $\mathcal{f}$ Comp Neurol 1988;274:60-76.

17 Leone M, Patruno G, Vescovi A, Bussone G. Neuroendocrine dysfunction in cluster headache. Cephalalgia 1990;10:235-9.

18 Fozard JR. The pharmacological basis of migraine treatment. In: Blau JN, ed. Migraine. London: Chapman and Hall, 1987:165-84.

19 Mohr E, Richter D. Vasopressin in the regulation of body

function. 7 Hypertens 1994;12:345-8.
20 Hardebo JE, Moskowitx MA. Synthesis of cluster headache pathophysiology. In: Olesen J, Tfelt-Hansen headache pathophysiology. In: Olesen J, Tfelt-Hansen P, Welch KMA, eds.
Press, 1993:569-76.

21 Moskowitx MA. Basic mechanisms in vascular headaches. Neurol Clin 1988;8:801-15.

22 Bussone G, Waldenlind E. Biochemistry, circannual and circadian rhythms, endocrinology, and immunology. In Olesen J, Tfelt-Hansen P, Welch KMA, eds. The headaches. New York: Raven Press, 1993:551-9. 